\title{
A Note on the Status of Dairy Farming in Galle District, Sri Lanka
}

Palapa Gamage Mihiri Kalpani, Kodithuwakku Arachchige Mangala Sudarshanie and Hemantha Chandani Edirisinghage Wegiriya*

Department of Zoology, University of Ruhuna, Matara 8100, Sri Lanka

\begin{abstract}
Present investigation was carried out to study the factors which affect milk production of dairy cattle in Labuduwa, Rathgama and Yakkalamulla veterinary ranges in Galle district, Sri Lanka. Breed type of cattle, insemination method, sex of the calves, milk production of mother cows, rearing methods and ectoparasitic tick infestations were studied. The studied cattle were belonged to cross breeds of Jersey, Friesian, Sahiwal and AFS (Australian friesian sahiwal)and Jersey was the most common breed. Sahiwal and AFS breeds tend to produce more male calves under artificial insemination. The milk production of mother cows reared under semi intensive management system was high $(\mathrm{p}<0.05)$. In addition, results revealed that the milk production of artificially inseminated mother cows was higher than that of the naturally bred mother cows ( $\mathrm{p}>0.05)$. Boophillus decolaratus was the only tick species present on studied calves with low percentage abundance (14.54\%) of male ticks compared to that of female ticks (85.45\%). Tick abundance was high in calves reared under free range management system. The tick abundance was high in Labuduwa range than Rathgama range ( $\mathrm{p}$ 0.05). According to the findings of the present study, the effect of the cattle management system has considerable impacts on milk production and tick infestations of dairy cattle in studied veterinary ranges in Galle district.
\end{abstract}

Key words: Milk production, cattle management systems, Boophillus decolaratus.

\section{Introduction}

Livestock farming is a key component in Sri Lankan agriculture and spread throughout all regions of Sri Lanka with dairying as the primary purpose. Large scale introduction of exotic dairy type cattle has contributed to improve the productivity of the dairy industry [1]. However, there has been a significant drop in the number of cattle during the past two decades. Many years ago, a large number of cattle were raised for milk production, and around $50 \%$ of families in Sri Lanka used cattle and buffaloes for agricultural work [2]. The last island-wide census of agriculture conducted in 2002 showed that the populations of the two species had declined to 1.1 and 0.36 million, respectively [3]. Consequently, Sri Lanka has serious problems in milk production and agricultural needs of the rural areas [2]. Therefore, it

*Corresponding author: Hemantha Chandani Edirisinghage Wegiriya, associate professor, research fields: entomology and animal physiology. E-mail: hemantha@zoo.ruh.ac.lk. is essential to increase dairy cattle farming in Sri Lanka to increase the milk production. The majority of cattle in Galle district is of the crossbred type, comprising mainly of crosses between the indigenous Bos indicus (Zebu) cattle and improved Zebu breeds from the Indian sub-continent, or between Zebu and Bos taurus (European/American) dairy breeds. The main improved Zebu breeds used in dairy production in Sri Lanka are Sindhi and Sahiwal, while the main European breeds used are Friesian and Jersey [3]. The unique characteristic of Sri Lankan dairy industry is that the bulk of milk production is handled by small-scale milk producers who are ignorant of economic aspects of milk production. Southern region of Sri Lanka comprises 5,305 livestock keepers with an estimated 38,000 of dairy cattle. Annual milk production in the region is approximately 4.7 million liters while daily milk production in the region is less than 20,000 liters [4]. As such, there is a need to strengthen dairying as an important enterprise in 
southern region. The major concern of dairy farmers is breeding of cattle for the milk and high quality offspring production. Successful farming systems produce almost one calf per animal annually. This target could be achieved through improved breeding practices [5]. Reproductive efficiency of the dairy herd is important to the economic success of the dairy operation and most dairy farmers tend to practice AI (Artificial insemination) as the preferred method of upgrading the productivity of their herds [3]. However, dairy farmers in rural areas in Galle district do not practice AI due to various reasons such as lack of facilities, high cost etc. Therefore, the natural breeding is the only available option for them [6]. It has been caused the less production in different breeds in such areas. Further Parasitic diseases are major problem in dairy industry not only in Galle district [7]. Among them ticks are the most important ecto-parasites of livestock [8] in tropical and sub-tropical areas, and are responsible for severe economic losses in livestock. The major losses, however, caused by ticks are due to their ability to transmit protozoan, rickettsial and viral diseases of livestock, which are of great economic importance world-wide. Tick-borne protozoan diseases (e.g. Theileriosis and Babesiosis) and rickettsial diseases (e.g. Anaplasmosis) and cowdriosis and tick-associated dermatophilosis are major health and management problems of livestock in many developing countries. The economically most important ixodid ticks of livestock in tropical regions belong to the genera of Hyalomma, Boophilus, Rhipicephalus and Amblyomma [7]. There are various ways to control ticks, but chemical control with acaricides was considered as one of the best methods. However, several studies have shown that ticks have developed resistance against a range of acaricides. Development of resistance to acaricides, chemical residues in food and the environment and the unsuitability of tick resistant cattle for all production systems are the known adverse effects of chemical control in dairy industry [7]. The major aim of this study was studying the status of dairy farming in Galle district. This study gives important information related to cattle farming in Galle district making successful the aim of study.

\section{Materials and Methods}

The study was carried out in three veterinary ranges selected from Galle district namely, Labuduwa, Rathgama and Yakkalamulla where people rear dairy cattle for their additional income. The area was selected, due to the availability of sufficient dairy cattle for the collection of data and as no surveys has been conducted to evaluate the status of calves in these farming systems. Dairy cows with 3 months old calves $(n=35)$ were selected for the study. Background information about cattle and their calves was collected using a questionnaire. The data was gathered by visiting individual dairy farmers. Monthly milk production data was recorded for six months starting from June. In addition, ectoparasites present in studied calves were recorded. Ticks were collected from regions of tail, perineal region and ear lobes as described by Alkareem et al. (2012). The numbers of ticks in a $5 \times 5 \mathrm{~cm}^{2}$ region of perineal region were recorded monthly since the 2nd month of the study. The collected tick samples were preserved in $70 \%$ alcohol solution [9]. In the laboratory each tick specimen was examined under dissecting microscope and identified using a taxonomic pictorial key of common ticks [10]. Minitab version 16.0 and Microsoft office Excel (Windows, 2007) were used to analyze the collected height, weight and tick abundance data. T-test and ANOVA test were used to assess if there is any statistical difference in various factors such as rearing method, breeding method, breed type and etc. with the milk production of cattle.

\section{Results and Discussion}

\subsection{Cattle Information}

The informations about cattle management practices and breeding methods at each study site that collected using the questionnaire are summarized in 
Table 1. In Yakkalamulla range available breeds were Friesian and Jersey and their calves were born under natural breeding and the population of dairy cows is less than the other two ranges. Most of farmers in Yakkalamulla range rear one or two female cows with one male. Only that male is used for the mating. Because of this reason, the chance for different breed types to be available in this area is less. Rathgama and Labuduwa ranges consist of calves born under AI. Therefore different breed types as Sahiwal an AFS (Australian friesian sahiwal) can be seen in these two ranges. Further Cross breed dairy cows are highly productive and they are the major contribution to household economics in the study area. When management system is considered free range management system is common in all ranges. In addition, semi intensive management system is also practiced in Rathgama and Labuduwa ranges. For Semi intensive management system farmers have to spend more time for maintenance as they have to supply water and food for cattle and calves. In Yakkalamulla range more lands are available for grazing. It may be the reason for using only free range management system in Yakkalamulla range. When free range management system is maintained farmers pay their attention on calves only at the evening and in general, the attention of farmers on calves is less than the other two ranges.

\subsection{Sex Ratio of Calves}

The sex ratio of studied calves is summarized in Table 2. Using AI technique is to get good quality calves and it will be more profitable if they can get more female calves through AI. Artificially bred, Jersey and Friesian breeds resulted 1:1 and 1:2 male to female ratio respectively. But in natural breeding, male: female sex ratio in Jersey breed and Friesian breed was 3:2 and 1:1 respectively. This indicates that AI is profitable for both breeds. However, for AFS and Sahiwal breeds male/female sex ratio under AI

Table 1 The information about cattle.

\begin{tabular}{|c|c|c|c|c|}
\hline Site name and breeding method & Management system & Breed of calves & No of calves & Sex \\
\hline \multirow{8}{*}{$\begin{array}{l}\text { Labuduwa site } \\
\text { Breeding method: } \\
\text { artificial insemination }\end{array}$} & \multirow{4}{*}{ Semi intensive } & Jersey & 01 & $\mathrm{~F}$ \\
\hline & & AFS & 01 & $\mathrm{~F}$ \\
\hline & & Sahiwal & 01 & $\mathrm{~F}$ \\
\hline & & Friesian & 01 & $\mathrm{M}$ \\
\hline & \multirow{4}{*}{ Free range } & AFS & 02 & $\mathrm{M}, \mathrm{F}$ \\
\hline & & Sahiwal & 03 & $\mathrm{M}$ \\
\hline & & Jersey & 07 & $M(5), F(2)$ \\
\hline & & Friesian & 02 & $\mathrm{~F}$ \\
\hline \multirow{8}{*}{$\begin{array}{l}\text { Rathgama site } \\
\text { Breeding method: } \\
\text { artificial insemination }\end{array}$} & \multirow{5}{*}{ Semi intensive } & Jersey & 00 & - \\
\hline & & AFS & 02 & M \\
\hline & & Sahiwal & 02 & $\mathrm{M}, \mathrm{F}$ \\
\hline & & Friesian & 00 & - \\
\hline & & Jersey & 02 & $\mathrm{~F}$ \\
\hline & \multirow{3}{*}{ Free range } & AFS & 02 & $\mathrm{M}, \mathrm{F}$ \\
\hline & & Sahiwal & 02 & M \\
\hline & & Friesian & 00 & - \\
\hline Yakkalamulla site & \multirow{2}{*}{ Free range } & Jersey & 05 & $\mathrm{M}(3), \mathrm{F}(2)$ \\
\hline Natural breeding & & Friesian & 02 & $\mathrm{M}, \mathrm{F}$ \\
\hline Breeding method & Breed type & No. of calves & \multicolumn{2}{|r|}{ Sex ratio $(M: F)$} \\
\hline \multirow{4}{*}{ Artificial } & Jersey & 10 & \multicolumn{2}{|r|}{$1: 1$} \\
\hline & AFS & 07 & \multicolumn{2}{|c|}{$4: 3$} \\
\hline & Sahiwal & 08 & \multicolumn{2}{|c|}{$3: 1$} \\
\hline & Friesian & 03 & \multicolumn{2}{|c|}{$1: 2$} \\
\hline \multirow{2}{*}{ Natural } & Jersey & 05 & \multicolumn{2}{|c|}{$3: 2$} \\
\hline & Friesian & 02 & \multicolumn{2}{|c|}{$1: 1$} \\
\hline
\end{tabular}


was 4:3 and 3:1 respectively. This may be not profitable for dairy farmers. Though AFS and Sahiwal are more suitable breeds for Sri Lanka, getting more male calves through AI may lower their preference by dairy farmers.

\subsection{Milk Production of Calves}

Milk production is an important secondary source of livelihood for the rural people and when the calf is grown the milk production of mother cow is gradually decreased. The mean milk production of mother cows whose calves born artificial and natural breeding is shown in Fig. 1. However, the dropping down of the milk production in mother cows whose calves born under artificial insemination was slow with the time. In addition, the milk production is also high in mother cow whose calf has been AI than NB (Natural breeding). It may be an advantage of artificial insemination. However there is no statistically significant difference observed between the milk productions of mother cows with their breeding method. Variance of mean milk production of mother cow with respect to the breed type of mother cow and calf is shown in Fig. 2. This graph shows that the milk production is high, when the mother cow and the calf belonged to the same breed $(\mathrm{P}>0.05)$. However this difference is not statistically significant. The mean milk production of mother cows reared under semi intensive and free range management system is shown in Fig. 3. The milk production of cows those reared under semi intensive management system is significantly higher $(\mathrm{P}<0.05)$ than those reared under the free range system. It is because of the better management in semi intensive management system than free range management system. It shows that there is an effect of the management system on the milk production of cow.

\subsection{Tick Infestation of Cattle}

Tick infestation studied was conducted on calves in Labuduwa and Rathgama veterinary ranges. All of the

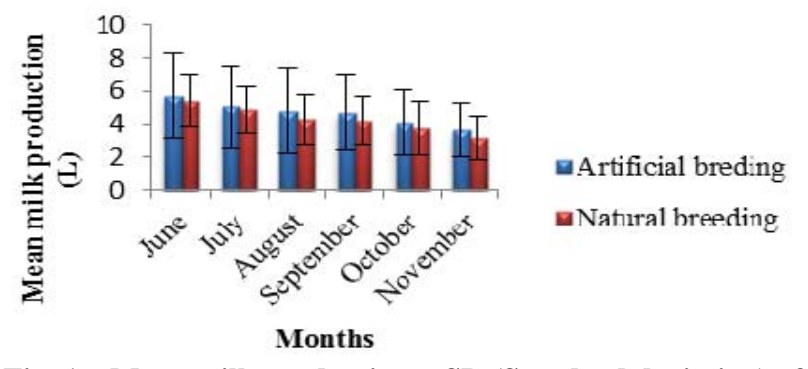

Fig. 1 Mean milk production \pm SD (Standard deviation) of mother cows whose calves born under artificial and natural breeding.

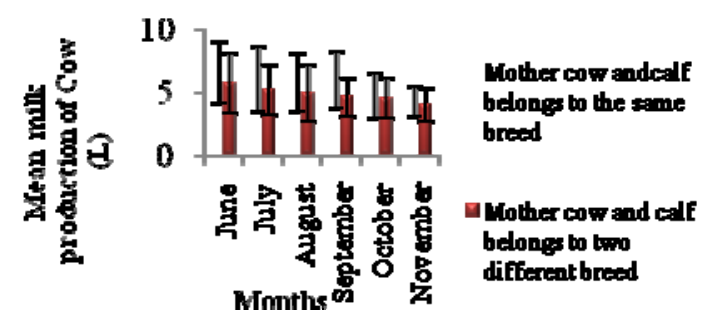

Fig. 2 Mean milk production \pm SD with respect to the breed type of mother cow and calf.

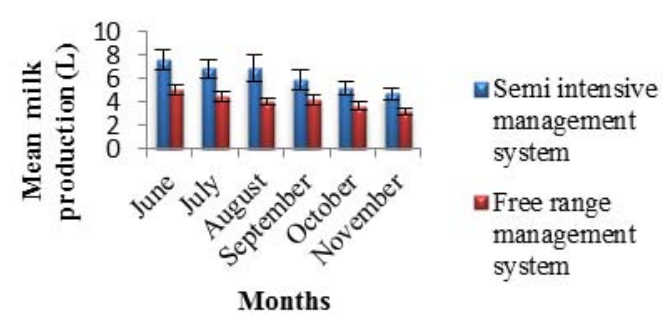

Fig. 3 Mean milk production \pm SE (Standard error) with respect to the management system of mother cow.

observed calves were found to be infested with hard ticks. Soft ticks were not recorded. Both male and female Boophilus decolaratus were recorded. In both ranges, cattle reared under semi intensive management practices were rarely infected by ticks. At the beginning of the study ticks were not counted as farmers followed tick control methods. Since the second month of the study ticks were counted after requesting farmers not to follow tick control methods until the end of the study. The abundance of ticks were ranked as High, Moderate and Low. These scores were given according to the number of ticks that were present in 5 square centimeter of perineal region of calves ( $<5$ low, 5-15 moderate, $>15$ high). In 
Table 3 Tick abundance of calves.

\begin{tabular}{llll}
\hline Site name & Month & Mean values \pm SE & Rank \\
\hline \multirow{4}{*}{ Labuduwa } & Aug. & $23.54 \pm 7.44$ & High \\
& Sep. & $22.31 \pm 5.09$ & High \\
& Oct. & $23.85 \pm 5.04$ & High \\
& Nov. & $31.54 \pm 8.98$ & High \\
\hline \multirow{5}{*}{ Rathgama } & Aug. & $9.00 \pm 3.59$ & Moderate \\
& Sep. & $11.29 \pm 4.76$ & Moderate \\
& Oct. & $12.00 \pm 4.66$ & Moderate \\
& Nov. & $14.43 \pm 5.07$ & Moderate \\
\hline
\end{tabular}

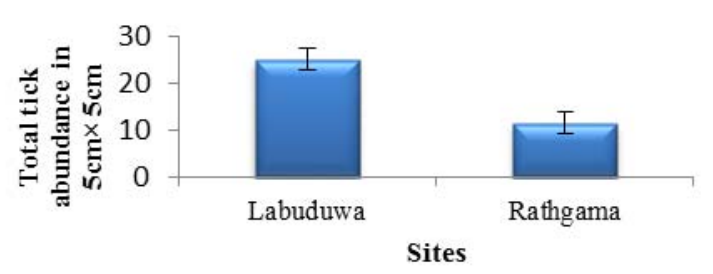

Fig. 4 Total tick abundance of studied calves in two veterinary ranges.

studied calves ticks were present not only in perennial region but also in ear region and tail region. However, the tick abundance was high in perennial region than the other two regions. Therefore, perennial region was selected to count ticks for the study. The tick abundance was shown in Table 3. The total tick abundance in the selected two ranges is shown in the Fig. 4 and total tick abundance is significantly high in Labuduwa range $(\mathrm{P}<0.05)$. In Rathgama range, tick abundance was moderate that and that indicates factors other than cattle management system caused the high abundance of ticks in Labuduwa range. According to the information collected through questionnaire the farmers in Rathgama range had applied tick control measures for a long time than farmers in Labuduwa range. It might cause low abundance of ticks on calves in Rathgama range. In addition, the amount of land with vegetation cover was higher in Labuduwa range than Rathgama range. Hard ticks generally spend much of their long life on the ground or on vegetation awaiting host [10]. The ecosystem with its vegetation cover and soils constitute a hiding place and source of parasitic infestation. The majority of livestock owners was busy and employed or has no time to concern about their calves. So the efficiency and management system were not in satisfactory level. As a result, ticks had more probability to invade calves reared under free range management system leading high tick infestations. However, the veterinary services in these areas were in a satisfactory level. According to the instructions, farmers apply control measures for ticks. The educational programs for dairy farmers and laborers will be a good solution in order to control the tick infestation of calves further.

\section{Conclusions}

Findings of this study conclude that livestock farmers should have given more emphasis on breeding methods and management systems to enhance the dairy industry in Galle district Sri Lanka.

\section{Acknowledgments}

Financial assistance given by Ruhuna University, Science Faculty Grant RU/SF/RP/2013/02 is acknowledged.

\section{References}

[1] Abeygunawardena, H. Rathnayaka, D. and Jayatilake, W. M. A. P. 1997. "Characteristics of Cattle Farming Systems in Sri Lanka,” J. Natn. Sci. coun. Sri Lanka, 25 (1): 25-38.

[2] Karunadasa, D. M. 2013. “An Evaluation of the Dairy Cattle Farming of Monaragala District in Sri Lanka”, A study with reference Pahalagama G. N. division of Buttala D. S. division. Department of Geography, University of Colombo.

[3] Perera, B. M. A. O. and Jayasuriya, M. C. N. 2008. “The Dairy Industry in Sri Lanka: Current Status and Future Directions for a Greater Role in National Development”, J. Natn. Sci. coun. Sri Lanka, 36: 115-26.

[4] De Silva, P. H. G. J. and Sandika, A. L 2012, “The Impact of Agricultural Credit and Farmer Trainings on Small Holder Dairy Production in Southern Region in Sri Lanka.” Iranian journal of applied animal science 2 (3): 265-9.

[5] Agric, J. S. 2012. "Effect of Breeding Method on Calf Sex and Postpartum Reproductive Performance of Cattle and Buffaloes." Animal Health Programme 28 (3): 469-76.

[6] Kono, H., Gunarathne, A., Kubota, S. and Karunagoda, K. 
2010. "Feed Management and Dairy Farm Efficiency in Sri Lanka: Direction of Technology in Tropical Dairy Farming”, University of Agriculture and Veterinary Medicine and Department of Agriculture.

[7] Rajput, Z. I., Chen, H. S., Arijo, W. A. G. and Xiao, C. 2006. "Importance of Ticks and their Chemical and Immunological Control in Livestock". Journal of Zhejiang University Science 7 (11): 912-21.

[8] Ravindran, V., Sriskandarajah, N. and Rajamahendran, R. 1996. "Diseases and Parasites of Domesticated Animals in Sri Lanka”,Science Education Series. No. 29. Natural resource energy and science authority.

[9] Alkareem, I. B. G. Abdelgadir, A. E. and Elmalik, K. H. 2012. "Study on Prevalence of Parasitic Diseases in Cattle in Abeyi Area-Sudan.”, Journal of Cell and Animal Biology 6 (6): 88-98.

[10] Pratt, H. D. and Litting, K. S. 1967. "Ticks of Public Health Importance and their Control." Department of health, education and welfare public health service, U.S. 30-6. 